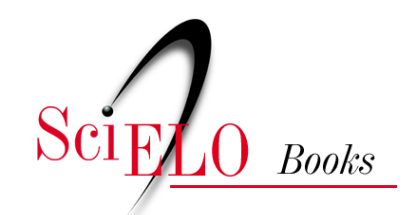

\title{
IV. À guisa de conclusão
}

\author{
Sonia Netto Salomão
}

\section{SciELO Books / SciELO Livros / SciELO Libros}

SALOMÃO, S.N. À guisa de conclusão. In: Machado de Assis e o cânone ocidental: itinerários de leitura [online]. 2nd ed. Rio de Janeiro: EDUERJ, 2019, pp. 401-408. ISBN: 978-65-990364-8-4. https://doi.org/10.7476/9786599036484.0012.

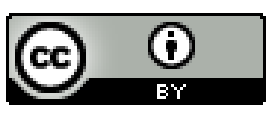

All the contents of this work, except where otherwise noted, is licensed under a Creative Commons Attribution 4.0 International license.

Todo o conteúdo deste trabalho, exceto quando houver ressalva, é publicado sob a licença Creative Commons Atribição 4.0.

Todo el contenido de esta obra, excepto donde se indique lo contrario, está bajo licencia de la licencia $\underline{\text { Creative }}$ Commons Reconocimento 4.0 . 


\section{IV. À guisa de conclusão}

Orador que me quiser ver aplaudi-lo, há de empregar dessas belas frases feitas, que, já estando em mim, ecoam de tal maneira, que me parece que eu é que sou o orador.

Machado de Assis.

$\mathrm{Na}$ releitura e reescritura dos cânones efetuadas pelo escritor carioca, tudo passa pelo filtro da brasilidade e da historicidade do seu discurso. Do ponto de vista crítico, o reconhecimento do leitor se dá pela capacidade machadiana de moldar o cânone ocidental aos exemplos locais. Nesse sentido, Machado traduz, reescreve, mistura, solicita a colaboraçáo do leitor. No processo, provoca a memória arcaica e coletiva: cria a sua cicatriz de Aquiles. Num segundo movimento, o autor de Quincas Borba parte do fato local, da história miúda, da anedota da comadre, elevando-a à máxima. A esse respeito, Italo Calvino, num instigante volume, pergunta-nos: por que ler os clássicos? E ele mesmo responde, na abertura do seu trabalho: "Os clássicos são aqueles livros dos quais, em 
geral, se ouve dizer: 'Estou relendo...' e nunca 'Estou lendo...".'. Acrescenta, mais adiante: "Toda primeira leitura de um clássico é na realidade uma releitura", continuando com uma nota explicativa que especifica a observação, tanto para os clássicos antigos como para os modernos:

Os clássicos são aqueles livros que chegam até nós trazendo consigo as marcas das leituras que precederam a nossa e atrás de si os traços que deixaram na cultura ou nas culturas que atravessaram (ou mais simplesmente na linguagem ou nos costumes). ${ }^{2}$

Coloco aqui um parêntese, extraído de um comentário de Alexandre Eulálio a respeito de um dos maiores críticos de Machado de Assis, Augusto Meyer:

E assim o moço modernista se descobrira muito próximo dos mesmos esgares e atitudes do escritor maior que tanto o haviam irritado antes. Mais de uma vez ouvi de Mestre Meyer a história essa (fala riograndense), - confesso que com alguma incredulidade de ainda ingênuo: a crisálida de livro contra Machado de Assis, que ele havia projetado a fim de insultar os filisteus, a meio caminho do voo se transformara no mais palpitante pulsar de admiração pelo primeiro alvo da diatribe. E o suposto motivo do ataque tornara-se tema decisivo da vida intelectual dele, atacante. ${ }^{3}$

O parêntese serve apenas para lembrar o quanto Machado foi atacado, e quanto de incompreensão sofreu a sua obra, prin-

1 Cf. I. Calvino, Por que ler os clássicos [1991], trad. de N. Moulin, São Paulo: Companhia de Bolso, 2002, p. 9.

2 Idem, p. 11.

3 Cf. A. Eulalio, "Em torno de uma carta de Machado de Assis", in Letterature D’America, Rivista Trimestrale, ano IV, n. 18, estate 1983, pp. 135-48. 
cipalmente no debate, hoje superado, entre localismo e universalismo. Como lembrou Carlos Fuentes, ${ }^{4}$ a respeito do contexto pós-colonial latino-americano, as imitaçóes absurdas do período pós-independência acabaram por formar uma civilização imediatista e solúvel: os escritores pensavam poder ser instantaneamente modernos, abolindo o passado e negando a tradição. A genialidade machadiana, frisa Fuentes, consistiu exatamente no contrário. A sua obra é permeada por uma convicção: não existe criação sem uma tradição que a nutra, assim como não existe tradição sem criação que a renove. Fuentes, de certa forma, atualiza a lição de Ernst Curtius que, como vimos no capítulo I, 1.2, repercorre a tradição ocidental, estabelecendo os topoi que formarão os cânones, num eterno jogo entre Antigos e Modernos; processo em que o clássico jamais deve congelar-se, permanecendo imó-vel numa espécie de mausoléu: deve, ao contrário, renascer, reviver, numa recriação moderna.

A este respeito ainda, compreende-se bem a admiração de Machado de Assis por José de Alencar. Machado soube avaliar como nenhum outro a estatura do autor de O Guarani, Iracema e Senhora num país sem tradição narrativa. À parte a grande prosa barroca de um Antônio Vieira, restava bem pouco para o romantismo que Alencar e Macedo (em segundo plano) puderam produzir. Náo se deve esquecer que o romantismo brasileiro nasceu em Paris com Gonçalves de Magalhães e que, no prefácio da Revista Niterói, publicada na Ville Lumière, em 1836, a epígrafe era: "tudo pelo Brasil e para o Brasil". O termo aparecia, no momento, em oposição ao "classicismo". Como pano de fundo, a grande tradição europeia que, no contexto brasileiro, excluía Portugal. Exclusão, no entanto, temperada pela "saudade" portuguesa e destinada a interpretar uma situaçáo local, valorizada segundo

4 Cf. C. Fuentes, "Machado de la Mancha”, in Revista Quimera, n. 175, 1998, pp. 8-16, depois traduzido em português: "O milagre de Machado de Assis", in Folha de S. Paulo, Caderno Mais, $1^{\circ}$ de outubro de 2000, pp. 4-11. 
os princípios de exaltação do movimento que propunham, justamente, o retorno ao passado e às tradiçóes nacionais. É quando entra em cena o indianismo.

Ao romantismo, o Brasil deve a sua independência literária, a conquista da liberdade de pensamento e de expressáo sem precedentes, e a aceleração do processo cultural que, em cerca de cinquenta anos, de 1800 a 1850, passa de uma situação indefinida, de um misto de neoclassicismo decadente, iluminismo revolucionário e exaltação nativista, a uma plêiade de poetas e narradores que começam a consolidar a literatura nacional, dando-lhe autonomia de forma, de técnica e de temas. Foi com esta situação de fato que Machado se confrontou no Brasil, tendo, naturalmente, como retaguarda, toda a tradição da literatura clássica greco-latina e da literatura portuguesa e francesa; esta última, aliás, a ditar as regras, em nível mundial, no segundo Oitocentos. Mas Machado também bebeu em Cervantes e na literatura setecentista inglesa, não se podendo esquecer, tampouco, da presença italiana, como buscamos reconstruir no terceiro capítulo.

Insistimos, no capítulo I, quanto ao processo das Memórias póstumas, o texto que maior desafio apresenta ao crítico, construindo-se como um hipertexto em que as entradas intertextuais e as reescrituras são muitas, metadiscursivas e ironicamente dessacralizantes, também. Um desafio, portanto, que faz parte da sua estratégia narrativa. Mas nem o Dom Casmurro, nem, tampouco, o Esaú e Jacó ou o Quincas Borba fogem a esse processo que, sem dúvida, se explica, do ponto de vista cultural, com a necessidade de se criar uma literatura nacional diversa da que existia no país. Procuramos mostrar um exemplo de diferença de modelos no capítulo I.4. É a partir das mudanças propostas no Memórias póstumas, portanto, que se pode compreender o valor do romance como divisor de águas não só na obra de Machado como na literatura brasileira como um todo. Essa obra expressa, de modo altissonante, aquele desejo de ruptura necessária. Mais, ainda: pode-se falar 
de uma "aventura da mimesis" nesse romance, no qual a arte ocupa o espaço da morte, já que se dá voz ao "defunto-autor". Abre-se igualmente um outro capítulo fundamental na obra machadiana: o da voz narrativa e do memorialismo. $\mathrm{O}$ aspecto fantástico e simultaneamente risonho da narrativa, repetimos, na ostentação poliglota das fontes dá um sabor barroco à narrativa que exerce, sem dúvida, bastante fascínio no leitor moderno, com a mistura de forma antiga com certo ar fresco de desrespeito pelas regras.

No estudo da antropofagia ante litteram do cânone ocidental (I, 2.2.2), percebemos que Machado antecipa a inversão de óptica proposta por Oswald de Andrade. O nosso canibal de sobrecasaca devorou, embora com espírito de "ruminante", a tradição clássica, sendo espantoso como ainda se possam descobrir modelos inéditos, como o que flagramos no corpus pseudo-hipocrático, no riso de Demócrito, enfim, de O alienista. Machado já havia teorizado sobre esse processo naquilo que chamamos de "Teoria da Chapa", sendo surpreendente, entre tantos exemplos, a ruminação de Dante (com direito a enxerto no Quincas Borba), da história e dos mitos grecoromanos. Necessário foi repercorrer os passos metodológicos da intertextualidade, para chegar a tais conclusôes. Nesta trajetória, a ópera italiana atualiza e restitui Shakespeare ao público culto carioca. O Dom Casmurro é também um Shakespeare lido por Verdi. Eis então que as disjunçôes machadianas se realizam de modo surpreendente. Como as serpentes do canto XXV do Inferno de Dante, que o autor carioca traduziu, ele também realiza as suas metamorfoses, sabendo que estava cumprindo uma proeza talvez tâo grande - se relevarmos a proporçấo de contexto - quanto a do poeta maior. É meticulosamente construído o drama do Dom Casmurro, sempre a partir do material autóctone, retirado do cotidiano miúdo dos tantos tipos que circulavam pela sociedade do Primeiro e do Segundo Reinado; o "molho" é próprio, mas temperado com a "especiaria" alheia. 
A articulação do aspecto histórico-cultural com as formulaçôes do gênero foi discutida levando-se em conta os cronótopos machadianos. Nesse item, recuperamos muito do clima científico do período no que diz respeito à questáo da memória. Quanto ao darwinismo social, presente na teoria do Humanitismo, cabe notar que, embora o texto basilar de Darwin - On the Origin of Species by Means of Natural Selection - date de 1859, publicado, portanto, cinco anos após o Système de politique positiviste, de Comte, a aceitação do darwinismo pela comunidade científica do período fez-se com muitas resistências, mesmo após o processo de difusão ocorrida nos anos imediatos. Se tomarmos como apoio a noção de paradigma, proposto como uma leitura não cumulativa do progresso científico segundo Thomas Kuhn, ${ }^{5}$ é difícil afirmar se teria havido ou não, na verdade, uma ruptura com os conceitos e métodos anteriores que se traduzisse pela substituição, em campo científico, de um modo interpretativo pelo outro, no Brasil de Machado de Assis; ou seja, é difícil saber quando se deu a mudança de paradigma. Foi o que demonstrou, para a França, Yvette Conry, ${ }^{6}$ que estudou o caso no país de Flaubert, atestando que só em 1900 se possa considerar efetivamente integrada a teoria darwinista, embora sempre de modo controverso. O que se pode afirmar com certeza é que Machado repudiou o evolucionismo como teoria mecanicista e aplicou o darwinismo social nos seus romances, com brioso estilo irônico, considerando-o um dado de fato. Basta pensar na Sofia do Quincas Borba e na Capitu do Dom Casmurro. ${ }^{7}$

5 Cf. T. S. Kuhn, A estrutura das revoluçôes cientificas (1977), trad. Beatriz V. Boeira e N. Boeira, São Paulo: Perspectiva, 1992.

6 Cf. Y. Conry, L'Introduction du darwinisme en France au XIXe siècle, Paris: Vrin, 1974, pp. 29-45.

7 Sabemos que Machado seguia o movimento filosófico e que possuía na sua biblioteca textos como La Selection naturelle (A. Wallace, 1872); La Descendance de l'homme et la selection sexuelle (Darwin, 1873), L'Origine des espèces au moyen de la selection naturelle... (Darwin, 1876); Introduction a la science sociale (Spencer, 1878); Le Darwinisme. Ce qu'ily a de vrai et de faux dans cette théorie (E. Hartmann, 1880), entre outros. Da análise da sua biblioteca, sabemos, também, que possuía livros 
Nesse item assinalamos, também, a teoria do falsete, já insinuada por Augusto Meyer, embora com abordagem psicológica e biográfica, enquanto, para nós, é proveitosa como articulação narrativa do ponto de vista, cuja teoria fomos encontrar num conto quase desconhecido de Machado que discorre sobre o tema e tem o sugestivo título homônimo: "Ponto de vista".

Quanto ao Machado lúdico, integra uma importante tradição de autores como Luciano, Dante, Rabelais, Cervantes, Borges, Zweig, Queneau, Calvino. No segundo capítulo, discutimos alguns aspectos da ironia machadiana: o riso clássico de Demócrito, adaptado a Itaguaí; o riso socrático que, no nosso entendimento, apresenta o semblante sério e ético do autor carioca e os jogos metalinguísticos que a sua língua literária construiu no âmbito do seu projeto estético. Aqui, examinamos muitos modelos de interdiscursividade, repetição e citação com rendimento humorístico.

Finalmente, mais de duzentas páginas deste estudo foram dedicadas, no terceiro capítulo, à reconstrução de um sistema italiano na cultura brasileira, principalmente o da Corte no Rio de Janeiro. Reunimos dados históricos que comprovam a inserção de Machado no conjunto de novidades trazidas da Itália: política, jornalismo, teatro e música, principalmente, durante os 46 anos de reinado de uma italiana: D. Teresa Cristina de Bourbon, esposa de Dom Pedro II. Ao mesmo tempo, pudemos constatar como Machado conheceu a Itália e a cultura latina através de filtros literários, muitas vezes franceses, como não poderia deixar de ser. Mas surpreendentes, neste campo, são as leituras machadianas e a sua capacidade fantasiosa e crítica de grande assimilador. De Campanella, Dante, da história romana, de Leopardi e da ópera italiana Machado soube absorver as melhores liçóes para os seus

pertencentes à área da filologia e da antropologia, publicados principalmente na década de 1870. Encontramos, assim, autores como Max Müller, Edward Tylor, Louis Buchner, John Lubbock ou Théodule Ribot. Cf. Glória Vianna, "Revendo a biblioteca de Machado de Assis", in J. L. Jobim (org.), cit., pp. 99-274. 
trabalhos. Descobrimos, num conto de 1886, "Curta história", o relato da experiência do público não conhecedor do italiano, por intermédio das traduçóes feitas para divulgar as peças ou as óperas, assim como vimos o efeito de emulação, que Machado descreve, como que antecipando os filmes de Woody Allen, em que os atores descem do palco e das telas cinematográficas para dançar com o público na plateia, participando, em seguida, da vida deles. Da riqueza das variantes que Machado conheceu por meio das óperas italianas, pôde modular o seu triângulo amoroso no Dom Casmurro. Chegamos a esta conclusão pela comparação filológica das traduçóes e dos textos machadianos do mesmo período do romance. Ao mesmo tempo, Machado na Itália é, hoje, uma realidade que se vai construindo pouco a pouco. Do confronto deste transplante interlinguístico e intersemiótico, como nos ensinou Jakobson, e a moderna teoria da tradução, compreendemos um pouco mais do nosso autor e da nossa cultura. Nesse capítulo, é desenvolvido, também, um método de crítica da tradução, a partir das obras machadianas traduzidas.

E o resto, perguntaria Machado? Naturalmente, muito falta ainda e já faz parte de um novo projeto a ser realizado. Dirá respeito à transmigração de ideias no segundo Oitocentos europeu e brasileiro. Ideias depois aclimatadas ou repudiadas pela inteligência ao mesmo tempo lúdica e crítica de Machado de Assis. 